\title{
Are Investors Reluctant to Realize Their Losses?
}

\author{
TERRANCE ODEAN*
}

\begin{abstract}
I test the disposition effect, the tendency of investors to hold losing investments too long and sell winning investments too soon, by analyzing trading records for 10,000 accounts at a large discount brokerage house. These investors demonstrate a strong preference for realizing winners rather than losers. Their behavior does not appear to be motivated by a desire to rebalance portfolios, or to avoid the higher trading costs of low priced stocks. Nor is it justified by subsequent portfolio performance. For taxable investments, it is suboptimal and leads to lower after-tax returns. Tax-motivated selling is most evident in December.
\end{abstract}

The TEndency to HOLD LOSERS too long and sell winners too soon has been labeled the disposition effect by Shefrin and Statman (1985). For taxable investments the disposition effect predicts that people will behave quite differently than they would if they paid attention to tax consequences. To test the disposition effect, I obtained the trading records from 1987 through 1993 for 10,000 accounts at a large discount brokerage house. An analysis of these records shows that, overall, investors realize their gains more readily than their losses. The analysis also indicates that many investors engage in taxmotivated selling, especially in December. Alternative explanations have been proposed for why investors might realize their profitable investments while retaining their losing investments. Investors may rationally, or irrationally, believe that their current losers will in the future outperform their current

\footnotetext{
* University of California, Davis. This paper is based on my dissertation at the University of California, Berkeley. I would like to thank an anonymous referee, Brad Barber, Peter Klein, Hayne Leland, Richard Lyons, David Modest, John Nofsinger, James Poterba, Mark Rubinstein, Paul Ruud, Richard Sansing, Richard Thaler, Brett Trueman, and participants at the Berkeley Program in Finance, the NBER behavioral finance meeting, the Financial Management Association Conference, the American Finance Association meetings, and seminar participants at UC Berkeley, the Yale School of Management, the University of California, Davis, the University of Southern California, the University of North Carolina, Duke University, the Wharton School, Stanford University, the University of Oregon, Harvard University, the Massachusetts Institute of Technology, the Amos Tuck School, the University of Chicago, the University of British Columbia, Northwestern University, the University of Texas, UCLA, the University of Michigan, and Columbia University for helpful comments. I would also like to thank Jeremy Evnine and especially the discount brokerage house that provided the data necessary for this study. Financial support from the Nasdaq Foundation is gratefully acknowledged.
} 


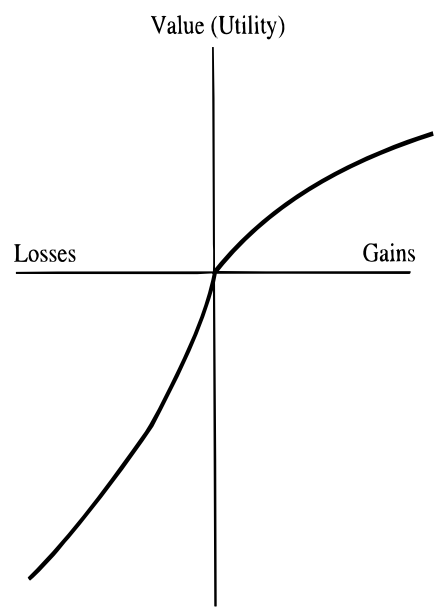

Figure 1. Prospect theory value function.

winners. They may sell winners to rebalance their portfolios. Or they may refrain from selling losers due to the higher transactions costs of trading at lower prices. I find, however, that when the data are controlled for rebalancing and for share price, the disposition effect is still observed. And the winning investments that investors choose to sell continue in subsequent months to outperform the losers they keep.

The next section of the paper discusses the disposition effect and literature related to it. Section II describes the data set and Section III describes the empirical study and its findings. Section IV discusses these findings and Section V concludes.

\section{The Disposition Effect}

\section{A. Prospect Theory}

The disposition effect is one implication of extending Kahneman and Tversky's (1979) prospect theory to investments. Under prospect theory, when faced with choices involving simple two and three outcome lotteries, people behave as if maximizing an "S"-shaped value function (see Figure 1). This value function is similar to a standard utility function except that it is defined on gains and losses rather than on levels of wealth. The function is concave in the domain of gains and convex in the domain of losses. It is also steeper for losses than for gains, which implies that people are generally risk-averse. Critical to this value function is the reference point from which gains and losses are measured. Usually the status quo is taken as the reference point; however, "there are situations in which gains and losses are 
coded relative to an expectation or aspiration level that differs from the status quo.... A person who has not made peace with his losses is likely to accept gambles that would be unacceptable to him otherwise" (Kahneman and Tversky (1979)).

For example, suppose an investor purchases a stock that she believes to have an expected return high enough to justify its risk. If the stock appreciates and the investor continues to use the purchase price as a reference point, the stock price will then be in a more concave, more risk-averse, part of the investor's value function. It may be that the stock's expected return continues to justify its risk. However, if the investor somewhat lowers her expectation of the stock's return, she will be likely to sell the stock. What if, instead of appreciating, the stock declines? Then its price is in the convex, risk-seeking, part of the value function. Here the investor will continue to hold the stock even if its expected return falls lower than would have been necessary for her to justify its original purchase. Thus the investor's belief about expected return must fall further to motivate the sale of a stock that has already declined than one that has appreciated. Similarly, consider an investor who holds two stocks. One is up; the other is down. If the investor is faced with a liquidity demand, and has no new information about either stock, she is more likely to sell the stock that is up.

Throughout this study, investors' reference points are assumed to be their purchase prices. Though the results presented here appear to vindicate that choice, it is likely that for some investments, particularly those held for a long time over a wide range of prices, the purchase price may be only one determinant of the reference point. The price path may also affect the level of the reference point. For example, a homeowner who bought her home for $\$ 100,000$ just before a real-estate boom and had the home appraised for $\$ 200,000$ after the boom may no longer feel she is "breaking even" if she sells her home for $\$ 100,000$ plus commissions. If purchase price is a major component, though not the sole component, of reference point, it may serve as a noisy proxy for the true reference point. Using the proxy in place of the true reference point will make a case for the disposition effect more difficult to prove. It seems likely that if the true reference point were available the statistical evidence reported here would be even stronger.

\section{B. An Alternative Behavioral Theory}

Investors might choose to hold their losers and sell their winners not because they are reluctant to realize losses but because they believe that today's losers will soon outperform today's winners. If future expected returns for the losers are greater than those for the winners, the investors' belief would be justified and rational. If, however, future expected returns for losers are not greater than those for winners, but investors continue to believe 
they are despite persistent evidence to the contrary, this belief would be irrational. In experimental settings Andreassen (1988) finds that subjects buy and sell stocks as if they expect short-term mean reversion. ${ }^{1}$

Most of the analysis presented here does not distinguish between prospect theory and an irrational belief in mean reversion as possible explanations for why investors hold losers and sell winners. It may be that investors themselves do not always make a clear distinction. For example, an investor who will not sell a stock for a loss might convince himself that the stock is likely to bounce back rather than admit his unwillingness to accept a loss.

\section{Taxes}

Investors' reluctance to realize losses is at odds with optimal tax-loss selling for taxable investments. For tax purposes investors should postpone taxable gains by continuing to hold their profitable investments. They should capture tax losses by selling their losing investments, though not necessarily at a constant rate. Constantinides (1984) shows that when there are transactions costs, and no distinction is made between the short-term and longterm tax rates (as is approximately the case from 1987 to 1993 for U.S. federal taxes ${ }^{2}$ ), investors should gradually increase their tax-loss selling from January to December. Dyl (1977), Lakonishok and Smidt (1986), and Badrinath and Lewellen (1991) report evidence that investors do sell more losing investments near the end of the year.

Shefrin and Statman (1985) propose that investors choose to sell their losers in December as a self-control measure. They reason that investors are reluctant to sell for a loss but recognize the tax benefits of doing so. The end of the year is the deadline for realizing these losses. So each year, investors postpone realizing losses until December when they require themselves to sell losers before the deadline passes.

A sophisticated investor could reconcile tax-loss selling with her aversion to realize losses though a tax-swap. By selling her losing stock and purchasing a stock with similar risk characteristics, she could realize a taxloss while maintaining the same risk exposure. Thaler (1985) argues that

\footnotetext{
${ }^{1}$ Subjects' tendencies to trade as if making regressive predictions diminish when their attention is focused on price changes rather than price levels (Andreassen (1988)) and when casual attributions for price trends, such as might normally be provided by the media, are made available (Andreassen (1987, 1990)).

${ }^{2}$ Prior to 1987 long-term capital gains tax rates were 40 percent of the short-term capital gains tax rates; from 1987 to 1993 long-term and short-term gains were taxed at the same marginal rates for lower income taxpayers. The maximum short-term rate at times exceeded the maximum long-term rate. In 1987 the maximum short-term rate was 38.5 percent and the maximum long-term rate was 28 percent. From 1988 to 1990 the highest income taxpayers paid a marginal rate of 28 percent on both long-term and short-term gains. In 1991 and 1992 the maximum long-term and short term-rates were 28 percent and 31 percent. In 1993 the maximum long-term and short-term rates were 28 percent and 39.6 percent.
} 
people tend to segregate different gambles into separate mental accounts. These are then evaluated separately for gains and losses. A tax-swap requires closing such an account for a loss, which people are reluctant to do.

\section{Previous Studies}

Previous research ${ }^{3}$ offers some support for the hypothesis that investors sell winners more readily than losers, but this research is generally unable to distinguish among various motivations investors might have for doing so. Investors may be behaviorally motivated to hold losers and sell winners, that is, they may have value functions like those described in prospect theory or they may incorrectly expect mean-reverting prices. There are also rational reasons why investors may choose to hold their losers and sell their winners: (1) Investors who do not hold the market portfolio may respond to large price increases by selling some of the appreciated stock to restore diversification to their portfolios (Lakonishok and Smidt (1986)); (2) Investors who purchase stocks on favorable information may sell if the price goes up, rationally believing that price now reflects this information, and may continue to hold if the price goes down, rationally believing that their information is not yet incorporated into price (Lakonishok and Smidt (1986)); and (3) Because trading costs tend to be higher for lower priced stocks, and because losing investments are more likely to be lower priced than winning investments, investors may refrain from selling losers simply to avoid the higher trading costs of low-priced stocks (Harris (1988)).

The contribution of this paper is to demonstrate, with market data, that a particular class of investors (those with discount brokerage accounts) sell winners more readily than losers. Even when the alternative rational motivations listed above are controlled for, these investors continue to prefer selling winners and holding losers. Their behavior is consistent with prospect theory; it is also consistent with a (mistaken) belief that their winners and losers will mean revert.

\footnotetext{
${ }^{3}$ Starr-McCluer (1995) finds that 15 percent of the stock-owning households interviewed in the 1989 and 1992 Surveys of Consumer Finances have paper losses of 20 percent or more. She estimates that in the majority of cases the tax advantages of realizing these losses would more than offset the trading costs and time costs of doing so. Heisler (1994) documents loss aversion in a small sample of futures speculators. In a study of individual federal tax returns, Poterba (1987) finds that although many investors do offset their capital gains with losses, more than 60 percent of the investors with gains or losses realized only gains. Weber and Camerer (1995) report experimental evidence of the disposition effect. Lakonishok and Smidt (1986) and Ferris, Haugen, and Makhija (1988) find a positive correlation between price change and volume. Bremer and Kato (1996) find the same correlation for Japanese stocks. Such a correlation could be caused by investors who prefer to sell winners and hold losers, but it could also be the result of buyers' trading preferences.
} 


\section{The Data}

The data for this study are provided by a nationwide discount brokerage house. From all accounts active in 1987 (those with at least one transaction), 10,000 customer accounts are randomly selected. The data are in three files: a trades file, a security number to CUSIP file, and a positions file. Only the first two files are used in this study. The trades file includes the records of all trades made in the 10,000 accounts from January 1987 through December 1993. This file has 162,948 records, each record is made up of an account identifier, the trade date, the brokerage house's internal number for the security traded, a buy-sell indicator, the quantity traded, the commission paid, and the principal amount. Multiple buys or sells of the same stock, in the same account, on the same day, are aggregated. The security number to CUSIP table translates the brokerage house's internal numbers into CUSIP numbers. The positions file contains monthly position information for the 10,000 accounts from January 1988 through December 1993. Each of its $1,258,135$ records is made up of the account identifier, year, month, internal security number, equity, and quantity. Accounts that were closed between January 1987 and December 1993 are not replaced; thus the data set may have some survivorship bias in favor of more successful investors. The data do not distinguish different account types. Therefore it is not possible to separate taxable accounts from tax-free accounts. Given the large sample size, we can expect the sample proportions of different account types to be close to the proportions for all of the brokerage's accounts. At the beginning of the data period, 20 percent of the brokerage's accounts were either IRA or Keogh accounts, and these accounts were responsible for 17.5 percent of all trades. The inclusion of these tax-exempt accounts will reduce tax-motivated trading in the data set, but with 80 percent of the accounts taxable, taxmotivated selling is easily detectable.

There are two data sets similar to this one described in the literature. Schlarbaum et al. (1978) and others analyze trading records for 2500 accounts at a large retail brokerage house for the period January 1964 to December 1970; Badrinath and Lewellen (1991) and others analyze a second data set provided by the same retail broker for 3000 accounts over the period January 1971 to September 1979. The data set studied here differs from these primarily in that it is more recent and comes from a discount broker. By examining discount brokerage records I can rule out the retail broker as an influence on observed trading patterns.

Badrinath and Lewellen (1991) look for evidence of tax-motivated trading and find that the ratio of stocks sold for a loss to those sold for a gain rises as the year progresses. Using a somewhat different measure, I also find evidence that investors increase their tax-motivated selling as the year progresses. However the focus of this paper, unlike that of Badrinath and Lewellen, is to test the disposition effect. As the next section describes, this is done by analyzing the rates at which investors realize gains and losses relative to their opportunities to do so. 


\section{Empirical Study}

\section{A. Methodology}

This study tests whether investors sell their winners too soon and hold losers too long. It also investigates tax-motivated trading in December. To determine whether investors sell winners more readily than losers, it is not sufficient to look at the number of securities sold for gains versus the number sold for losses. Suppose investors are indifferent to selling winners or losers. Then in an upward-moving market they will have more winners in their portfolios and will tend to sell more winners than losers even though they had no preference for doing so. ${ }^{4}$ To test whether investors are disposed to selling winners and holding losers, we must look at the frequency with which they sell winners and losers relative to their opportunities to sell each.

By going through each account's trading records in chronological order, I construct for each date a portfolio of securities for which the purchase date and price are known. Clearly this portfolio represents only part of each investor's total portfolio. In most accounts there will be securities that were purchased before January 1987 for which the purchase price is not available, and investors may also have other accounts that are not part of the data set. Though the portfolios constructed from the data set are only part of each investor's total portfolio, it is unlikely that the selection process will bias these partial portfolios toward stocks for which investors have unusual preferences for realizing gains or losses.

I obtain information on splits and dividends as well as other price data needed for this study from the 1993 Center for Research in Security Prices daily stock file for NYSE, AMEX, and Nasdaq stocks. The study is limited to stocks for which this information is available. Of the 10,000 accounts, 6,380 trade stocks in the CRSP file for a total of 97,483 transactions.

Each day that a sale takes place in a portfolio of two or more stocks, I compare the selling price for each stock sold to its average purchase price to determine whether that stock is sold for a gain or a loss. Each stock that is in that portfolio at the beginning of that day, but is not sold, is considered to be a paper (unrealized) gain or loss (or neither). Whether it is a paper gain or loss is determined by comparing its high and low price for that day (as obtained from CRSP) to its average purchase price. If both its daily high and low are above its average purchase price it is counted as a paper gain; if they are both below its average purchase price it is counted as a paper loss; if its average purchase price lies between the high and the low, neither a gain or loss is counted. On days when no sales take place in an account, no gains or losses, realized or paper, are counted.

\footnotetext{
${ }^{4}$ In Badrinath and Lewellen (1991) 49 percent of all round-trip sales are for a loss. In my database only 43 percent of such sales are for a loss. The difference could be due to different trading practices by retail and discount investors, but quite likely it simply reflects the greater rise in prices during the period I examine.
} 
Suppose, for example, that an investor has five stocks in his portfolio, A, B, C, D, and E. A and B are worth more than he paid for them; C, D, and E are worth less. Another investor has three stocks F, G, and $\mathrm{H}$ in her portfolio. $\mathrm{F}$ and $\mathrm{G}$ are worth more than she paid for them; $\mathrm{H}$ is worth less. On a particular day the first investor sells shares of $\mathrm{A}$ and of $\mathrm{C}$. The next day the other investor sells shares of F. The sales of A and F are counted as realized gains. The sale of C is a realized loss. Since B and G could have been sold for a profit but weren't, they are counted as paper gains. D, E, and $\mathrm{G}$ are paper losses. So for these two investors over these two days, two realized gains, one realized loss, two paper gains, and three paper losses are counted. Realized gains, paper gains, realized losses, and paper losses are summed for each account and across accounts. Then two ratios are calculated:

$$
\begin{aligned}
& \frac{\text { Realized Gains }}{\text { Realized Gains + Paper Gains }}=\text { Proportion of Gains Realized (PGR) } \\
& \frac{\text { Realized Losses }}{\text { Realized Losses + Paper Losses }}=\text { Proportion of Losses Realized (PLR) }
\end{aligned}
$$

In the example PGR $=1 / 2$ and PLR $=1 / 4$. A large difference in the proportion of gains realized (PGR) and the proportion of losses realized (PLR) indicates that investors are more willing to realize either gains or losses.

Any test of the disposition effect is a joint test of the hypothesis that people sell gains more readily than losses and of the specification of the reference point from which gains and losses are determined. Some possible choices of a reference point for stocks are the average purchase price, the highest purchase price, the first purchase price, or the most recent purchase price. The findings of this study are essentially the same for each choice; results are reported for average purchase price. Commissions and dividends may or may not be considered when determining reference points, and profits and losses. Although investors may not consider commissions when they remember what they paid for a stock, commissions do affect capital gains and losses. And because the normative standard to which the disposition effect is being contrasted is optimal tax-motivated selling, commissions are added to the purchase price and deducted from the sales price in this study except where otherwise noted. Dividends are not included when determining which sales are profitable because they do not affect capital gains and losses for tax purposes. The primary finding of the paper, that investors are reluctant to sell their losers and prefer to sell winners, is unaffected by the inclusion or exclusion of commissions or dividends. In determining whether the stocks that are not sold on a particular day could have been sold for a gain or a loss, the commission for the potential sale is assumed to be the average commission per share paid when the stock was purchased. ${ }^{5}$ All gains and losses are calculated after adjusting for splits.

\footnotetext{
${ }^{5}$ If, for potential sales, the commission is instead assumed to be the same percentage of principal as paid when the stock was purchased, the results do not significantly change.
} 
Table I

\section{PGR and PLR for the Entire Data Set}

This table compares the aggregate Proportion of Gains Realized (PGR) to the aggregate Proportion of Losses Realized (PLR), where PGR is the number of realized gains divided by the number of realized gains plus the number of paper (unrealized) gains, and PLR is the number of realized losses divided by the number of realized losses plus the number of paper (unrealized) losses. Realized gains, paper gains, losses, and paper losses are aggregated over time (19871993) and across all accounts in the data set. PGR and PLR are reported for the entire year, for December only, and for January through November. For the entire year there are 13,883 realized gains, 79,658 paper gains, 11,930 realized losses, and 110,348 paper losses. For December there are 866 realized gains, 7,131 paper gains, 1,555 realized losses, and 10,604 paper losses. The $t$-statistics test the null hypotheses that the differences in proportions are equal to zero assuming that all realized gains, paper gains, realized losses, and paper losses result from independent decisions.

\begin{tabular}{lccr}
\hline & Entire Year & December & Jan.-Nov. \\
\hline PLR & 0.098 & 0.128 & 0.094 \\
PGR & 0.148 & 0.108 & 0.152 \\
Difference in proportions & -0.050 & 0.020 & -0.058 \\
$t$-statistic & -35 & 4.3 & -38
\end{tabular}

There are two hypotheses to be tested. The first is that investors tend to sell their winners and hold their losers. Stated in terms of realization rates for gains and losses this is:

Hypothesis 1: Proportion of Gains Realized > Proportion of Losses Realized (for the entire year).

The null hypothesis in this case is that PGR $\leq$ PLR. The second hypothesis is that in December investors are more willing to sell losers and less willing to sell winners than during the rest of the year. That is:

Hypothesis 2: Proportion of Losses Realized - Proportion of Gains Realized in December > Proportion of Losses Realized - Proportion of Gains Realized in January-November.

The null hypothesis here is: PLR - PGR in December $\leq$ PLR - PGR in January through November.

\section{B. Results}

Table I reports the PGR realized and the PLR realized for the entire year, for January through November, and for December. We see that for the entire year investors do sell a higher proportion of their winners than of their losers. For both Hypothesis 1 and Hypothesis 2 the null hypotheses can be rejected with a high degree of statistical significance. A one-tailed test of the first null hypothesis, PGR $\leq \mathrm{PLR}$, is rejected with a $t$-statistic greater than 35. The second null hypothesis, PLR - PGR in December $\leq$ PLR - PGR in 
January through November, is also rejected ( $t$ equals 16$)$. These tests count each sale for a gain, sale for a loss, paper gain on the day of a sale, and paper loss on the day of a sale as separate independent observations. ${ }^{6}$ These observations are aggregated across investors. This independence assumption will not hold perfectly. For example, suppose an investor chooses not to sell the same stock on repeated occasions. It is likely that the decision not to sell on one date is not independent of the decision not to sell on another date. Alternatively, two investors may be motivated to sell the same stock on, or about, the same day because they receive the same information. This lack of independence will inflate the test statistics, though it won't bias the observed proportions. For Hypotheses 1 and 2 the null hypotheses are rejected with such a high degree of statistical significance that some lack of independence is not problematic. In the following discussion, the data are, at times, divided into several partitions (e.g., Figure 2 and Table VI). Where $t$-statistics for individual partitions approach the conventional thresholds of statistical significance, they should be viewed with some skepticism.

To gain some perspective into how critical the independence assumptions made above are to the primary finding of this paper-that investors realize gains too soon and hold losers too long-it is instructive to look at an alternative test. Suppose that instead of assuming that independence exists at a transactional level we assume only that it exists at an account level. That is, we assume that the proportions of gains and losses realized in each account are independent of those realized in other accounts. PGR and PLR are then estimated for each account and their difference, PGR - PLR, is calculated for each account. The average account PGR is 0.57 , the average account PLR is 0.36 , the average of PGR - PLR is 0.21 , and the hypothesis that the mean of PGR - PLR is less than or equal to zero is rejected with a $t$-statistic of 19. ${ }^{7}$ This alternative test also attempts to control for dependence caused by common information. To do this the sale of a stock is only counted if no sale has been previously counted for that stock in any account within a week before or after the sale date. That is, no two sales of the same stock within a week of each other are counted. Similarly, no two unrealized paper losses or gains of the same stock within a week of each other are counted. This test provides an alternative to the one reported in Table I and throughout the rest of the paper, but it is not without drawbacks. The previous test, in

\footnotetext{
${ }^{6}$ To calculate the $t$-statistics in Table I, the standard error for the difference in the proportions PGR and PLR is:

$$
\sqrt{\frac{\mathrm{PGR}(1-\mathrm{PGR})}{n_{r g}+n_{p g}}+\frac{\mathrm{PLR}(1-\mathrm{PLR})}{n_{r l}+n_{p l}}}
$$

where $n_{r g}, n_{p g}, n_{r l}$, and $n_{p l}$ are the number of realized gains, paper gains, realized losses, and paper losses.

${ }^{7}$ An account is included in this test only if the denominators for both PGR and for PLR are nonzero for that account. There are 1893 such accounts. These same accounts are used to calculate share-based and dollar-based PGR and PLR.
} 


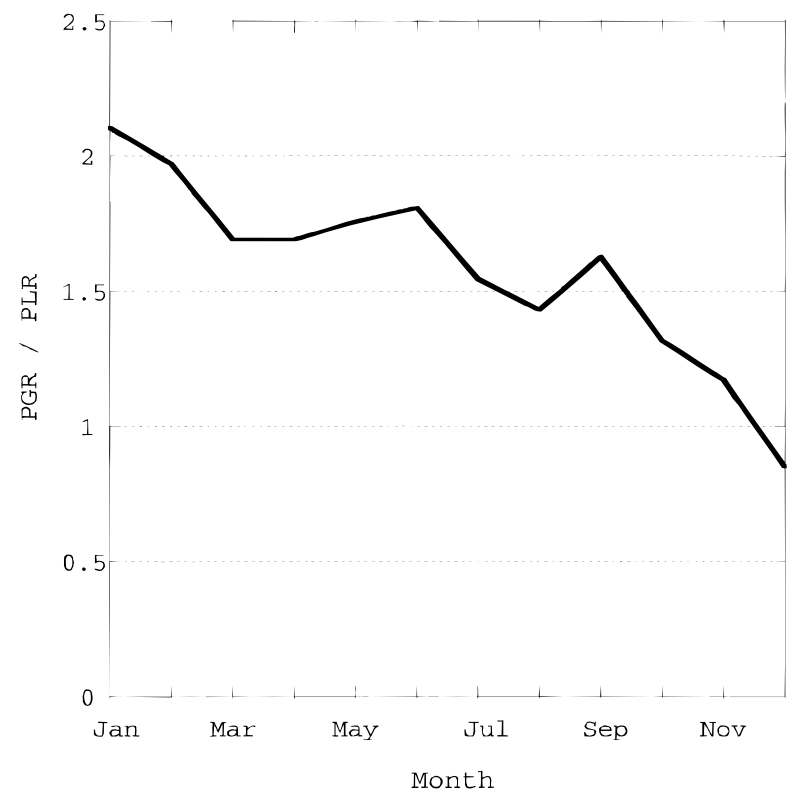

Figure 2. Ratio of the Proportion of Gains Realized (PGR) to the Proportion of Losses Realized (PLR) for each month. PGR is the number of realized gains divided by the number of realized gains plus the number of paper (unrealized) gains, and PLR is the number of realized losses divided by the number of realized losses plus the number of paper (unrealized) losses. Realized gains, paper gains, losses, and paper losses are aggregated over time (19871993) and across all accounts in the data set.

effect, weights each account by the number of realized and paper gains and losses in that account. This alternative test weights each account equally, which means we ignore the fact that accounts with more transactions provide more accurate estimates of their actual PGR and PLR. In other words, by treating each account the same, we assume that the observed account PGRs and PLRs are homoskedastic when they are clearly heteroskedastic. However, to properly weight for this heteroskedasticity we need to know the degree of independence of transactions within accounts, which is exactly the issue this test is intended to circumvent. It is presented here simply to demonstrate that when a different set of independence assumptions is made, the null to Hypothesis 1 is still rejected at a very significant level.

It should be noted that the PGR and the PLR measures are dependent on the average size of the portfolios from which they are calculated. When the portfolio sizes are large, both of these proportions will be smaller. Thus these proportions are smaller for traders who trade frequently and generally have larger portfolios than for those who trade less frequently. When PGR and PLR are calculated for Table I, the accounts with more trades weigh more heavily than those with fewer trades. In the alternative specification described in the last paragraph all accounts are weighted equally. For this 
reason PGR and PLR are both larger in the alternative specification than in Table I. Of primary interest is not the individual values of PGR and PLR, but their values relative to each other.

Throughout this paper PGR and PLR are calculated in terms of trades and potential trades. An alternative specification is to calculate them in terms of number of shares traded and potential number of shares traded. When gains, losses, paper gains, and paper losses are aggregated across accounts before calculating PGR and PLR, as is done throughout most of this paper, measuring in shares further complicates the question of independence. However, if PGR and PLR are first calculated for each account and then the mean of PGR - PLR is calculated-as in the alternative test described in the previous paragraph-independence is assumed only between accounts. When this alternative test is done for PGR and PLR based on shares rather than trades, the results are virtually unchanged: average PGR is 0.58 , average PLR is 0.36 , and the null hypothesis that the mean of PGR - PLR is less than or equal to zero is rejected with a $t$-statistic of $18 .{ }^{8}$

Suppose investors frequently realize small gains and less frequently take large losses. It is then possible that they are selling similar proportions of the values of their gains and losses, though realizing gains at a higher rate on a trade-counted basis. This is, however, not the case. I calculate the average PGR and PLR per account by measuring losses, gains, potential losses, and potential gains in terms of dollars rather than shares or trades. When, as before, no two sales or potential sales of the same stock within a week of each other are counted, the average dollar-based PGR is 0.58 and the average dollar-based PLR is 0.42 . The hypothesis that the mean of PGR - PLR is less than or equal to zero is rejected with a $t$-statistic of $13 .{ }^{9}$

In Table I the ratio of PGR to PLR for the entire year is a little over 1.5, indicating that a stock that is up in value is more than 50 percent more likely to be sold from day to day than a stock that is down. In Weber and Camerer's (1995) experimental studies of the disposition effect, a stock that is up is also about 50 percent more likely to be sold than one that is down. Figure 2 charts the ratio of PGR to PLR for each month. This ratio declines from 2.1 in January to 0.85 in December. This decline is consistent with Constantinides' tax-loss selling model and suggests that at least some investors pay attention to tax-motivated selling throughout the year. From January through November, however, the observed ratio of PGR to PLR is greater

\footnotetext{
${ }^{8}$ As in the previous test no two sales or potential sales of the same stock within a week of each other are counted here. If sales and potential within a week of each other are also counted, share-based PGR is 0.51 and share-based PLR is 0.31 .

9 To examine this issue from another perspective, I look at each year in each portfolio and tally the total number of years for which both potential gains and potential losses are present in the portfolio and either net gains or net losses are realized. Net dollar gains are realized for 2,116 of these years and net dollar losses for 1,477 years. This indicates that, in most cases, large losses are not offsetting small gains.
} 
than 1 and the hypothesis that the population ratio is less than or equal to 1 is rejected in each of these months with $t$-statistics ranging from 3.6 in November to 18 in January. ${ }^{10}$

To test the robustness of these results the data set is partitioned into two time periods and also into two groups of traders. Table II displays results when the data set is partitioned into stocks sold from 1987 to 1990 and 1990 to 1993 , and when it is partitioned into the decile of traders who trade most frequently and the nine deciles of traders who trade least frequently. In the data set, the most active 10 percent of the traders account for 57 percent of all stock trades. In both time periods and for both the frequent and the infrequent traders, a significantly greater proportion of all possible gains than of all possible losses is realized throughout the year ( $t$ greater than 22 , in all cases). In December, losses are realized at a higher rate relative to gains than during the rest of the year, indicating that investors are realizing tax losses in December. Due to how portfolios are reconstructed over time, average portfolio sizes are larger for the later years of the sample. PGR and PLR are therefore smaller for the second temporal partition, just as they are smaller for the partition of frequent traders.

One reason investors might choose to sell winners rather than losers is that they anticipate a change in the tax law under which capital gains rates will rise. The tax law of 1986 made such a change. If investors sold off winners in anticipation of higher tax rates, they might have entered 1987 with a larger percentage of losers in their portfolio than usual. Because such stocks are purchased prior to 1987 they would not show up in the portfolios reconstructed here. It is possible therefore that the rate at which winners are being realized relative to losers is lower in the investors' total portfolio than in the partial reconstructed portfolios. As old stocks are sold and new ones purchased the partial portfolios become more and more representative of the total portfolio. We would expect that if a sell-off of winners in anticipation of the 1986 tax law affects the observed rate at which gains and losses are realized in the partial portfolios, that effect would be greater in the first part of the sample period than in the last part. However the ratio PGR/PLR is virtually the same for the periods 1987 to 1990 and 1991 to 1993.

\footnotetext{
${ }^{10}$ In Tables I-VI, realized and unrealized losses are tabulated on days that sales took place in portfolios of two or more stocks. One objection to this formulation is that for portfolios that hold only winners or only losers an investor cannot choose whether to sell a winner or to sell a loser, but only which winner or loser to sell. Another objection is that if an investor has net capital losses of more than $\$ 3,000$ for the current year (in non-tax-deferred accounts) it may be normative for that investor to choose to sell a winner rather than a loser. I have repeated the analyses reported in the tables subject to the additional constraints that there be at least one winner and one loser in a portfolio on the day of a sale for that day to be counted and that the net realized capital losses for the year to date in the portfolio be less than $\$ 3,000$. When these constraints are imposed, the difference in PGR and PLR is, for each analysis, greater. For example, for the entire sample and the entire year (as in Table I) there are 10,111 realized gains, 71,817 paper gains, 5,977 realized losses, and 94,419 paper losses. Thus the PLR is 0.060 ; the PGR is 0.123 ; their difference is 0.063 ; and the $t$-statistic for the difference in proportions is 47 .
} 
Table II

\section{PGR and PLR Partitioned by Period and Trading Activity}

This table compares the aggregate Proportion of Gains Realized (PGR) to the aggregate Proportion of Losses Realized (PLR), where PGR is the number of realized gains divided by the number of realized gains plus the number of paper (unrealized) gains, and PLR is the number of realized losses divided by the number of realized losses plus the number of paper (unrealized) losses. The data are partitioned into the periods 1987-1990 and 1990-1993 and into the 10 percent of the accounts that trade most frequently and the 90 percent that trade least frequently. For 1987-1990 there are 7,280 realized gains, 28,998 paper gains, 7,253 realized losses, and 50,540 paper losses. For 1990-1993 there are 6,603 realized gains, 50,660 paper gains, 4,677 realized losses, and 59,808 paper losses. For frequent traders there are 10,186 realized gains, 75,182 paper gains, 8,886 realized losses, and 103,096 paper. For infrequent traders there are 3,697 realized gains, 4,476 paper gains, 3,042 realized losses, and 7,251 paper losses. The $t$-statistics test the null hypotheses that the differences in proportions are equal to zero assuming that all realized gains, paper gains, realized losses, and paper losses result from independent decisions.

\begin{tabular}{|c|c|c|c|c|}
\hline & 1987-1990 & 1991-1993 & $\begin{array}{c}\text { Frequent } \\
\text { Traders }\end{array}$ & $\begin{array}{c}\text { Infrequent } \\
\text { Traders }\end{array}$ \\
\hline Entire year PLR & 0.126 & 0.072 & 0.079 & 0.296 \\
\hline Entire year PGR & 0.201 & 0.115 & 0.119 & 0.452 \\
\hline Difference in proportions & -0.075 & -0.043 & -0.040 & -0.156 \\
\hline$t$-statistic & -30 & -25 & -29 & -22 \\
\hline December PLR & 0.143 & 0.110 & 0.095 & 0.379 \\
\hline December PGR & 0.129 & 0.097 & 0.084 & 0.309 \\
\hline Difference in proportions & 0.014 & 0.013 & 0.010 & 0.070 \\
\hline$t$-statistic & 1.9 & 2.3 & 2.3 & 3.5 \\
\hline Jan.-Nov. PLR & 0.123 & 0.069 & 0.078 & 0.282 \\
\hline Jan.-Nov. PGR & 0.207 & 0.117 & 0.123 & 0.469 \\
\hline Difference in proportions & -0.084 & -0.048 & -0.045 & -0.187 \\
\hline$t$-statistic & -32 & -27 & -31 & -25 \\
\hline
\end{tabular}

Table III reports the average returns since the day of purchase for realized and paper winners and losers. In December the losses that are realized are of much greater magnitude than those realized throughout the rest of the year. This is additional evidence that some investors do engage in taxmotivated selling in December.

Lakonishok and Smidt (1986) suggest that investors might sell winners and hold on to losers in an effort to rebalance their portfolios. We expect that investors who are rebalancing will sell a portion, but not all, of their shares of winning stocks. A sale of the entire holding of a stock is most likely not motivated by the desire to rebalance. So to eliminate trades that may be motivated by a desire to rebalance, I calculate PGR and PLR using only sales that are of an account's entire position in a stock (and using paper gains and losses on the days of those sales). There may be some cases where shares of a stock are already in the portfolio before 1987 and then additional shares are purchased. For these, the sale of all shares purchased after 1987 


\section{Table III}

\section{Average Returns}

This table reports the mean return realized on stocks sold for a gain and on stocks sold for a loss. It also reports mean return that could be realized by stocks that are not sold on days that other stocks in the same portfolio are sold. These stocks are classified as paper gains and paper losses. For all accounts over the entire year, there are 13,883 realized gains, 79,658 paper gains, 11,930 realized losses, and 110,348 paper losses. For all accounts during the month of December, there are 866 realized gains, 7,131 paper gains, 1,555 realized losses, and 10,604 paper losses.

\begin{tabular}{lccc}
\hline & Jan.-Nov. & December & Entire Year \\
\hline Return on realized gains & 0.275 & 0.316 & 0.277 \\
Return on paper gains & 0.463 & 0.500 & 0.466 \\
Return on realized losses & -0.208 & -0.366 & -0.228 \\
Return on paper losses & -0.391 & -0.417 & -0.393 \\
\hline
\end{tabular}

may not amount to the sale of all shares held. So this removal of sales that could be motivated by diversification is not perfect. Even so, if the preference for selling winners is due to rebalancing, removing most rebalancingmotivated trades will greatly reduce the preference for selling winners.

In Table IV, for the entire year, when partial sales are ignored the preference for selling winners rather than losers is not substantially changed. The tendency to sell winners and hold losers does not appear to be the result of rebalancing. When partial sales are ignored, investors realize losses in December at an even higher rate relative to realizing gains. Perhaps this is because investors who are intentionally realizing tax losses choose to sell their entire position in the losing stock.

Investors who sell winners for the purpose of rebalancing their portfolios are likely to make new purchases. In an alternative effort to eliminate trades that may be motivated by a desire to rebalance, I calculate PGR and PLR using only sales for which there is no new purchase into a portfolio on the sale date or during the following three weeks (and using paper gains and losses on the days of those sales). Table $\mathrm{V}$ reports that when sales motivated by a desire to rebalance are eliminated in this way, investors continue to prefer to sell winners. Once again, investors realize losses at a higher rate than gains in December.

Another reason investors might sell winners and hold losers is that they expect the losers to outperform the winners in the future. An investor who buys a stock because of favorable information may sell that stock when it goes up because she believes her information is now reflected in the price. On the other hand, if the stock goes down she may continue to hold it, believing that the market has not yet come to appreciate her information. Investors could also choose to sell winners and hold losers simply because they believe prices mean revert. I test whether such beliefs are justified, ex post. 
Table IV

\section{PGR and PLR When the Entire Position in a Stock Is Sold}

This table compares the aggregate Proportion of Gains Realized (PGR) to the aggregate Proportion of Losses Realized (PLR), where PGR is the number of realized gains divided by the number of realized gains plus the number of paper (unrealized) gains, and PLR is the number of realized losses divided by the number of realized losses plus the number of paper (unrealized) losses. In this table losses and gains are counted only if a portfolio's total position in a stock was sold that day. Paper (unrealized) gains and losses are counted only if the portfolio's total position in another stock held in the portfolio was sold that day. Realized gains, paper gains, losses, and paper losses are aggregated over time (1987-1993) and across all accounts in the dataset. PGR and PLR are reported for the entire year and for December only. For the entire year there are 10,967 realized gains, 36,033 paper gains, 9,476 realized losses, and 51,502 paper losses. For December there are 666 realized gains, 3,440 paper gains, 1,171 realized losses, and 4,759 paper losses. The $t$-statistics test the null hypotheses that the differences in proportions are equal to zero assuming that all realized gains, paper gains, realized losses, and paper losses result from independent decisions.

\begin{tabular}{lcc}
\hline & Entire Year & December \\
\hline PLR & 0.155 & 0.197 \\
PGR & 0.233 & 0.162 \\
Difference in proportions & -0.078 & 0.035 \\
$t$-statistic & -32 & 4.6 \\
\hline
\end{tabular}

Table VI reports excess returns for periods following the sale of a winning stock or the observation of a paper loss. Three investment horizons are examined: 84 trading days, which is the approximate median in sample holding period for stocks, ${ }^{11} 254$ trading days (one year), which is Benartzi and Thaler's (1995) estimate of the average investor's investment horizon, and 504 trading days (two years), which is how often, on average, New York Stock Exchange equities turned over during this period. Returns are calculated in excess of the CRSP value-weighted index. For winners that are sold, the average excess return over the following year is 3.4 percent more than it is for losers that are not sold. Investors who sell winners and hold losers because they expect the losers to outperform the winners in the future are, on average, mistaken. The superior returns to former winners noted here are consistent with Jegadeesh and Titman's (1993) finding of price momentum in security returns at horizons of up to eighteen months, though DeBondt and Thaler (1985, 1987) find price reversals at longer horizons of three to five years. ${ }^{12}$

${ }^{11}$ Note that the in-sample median holding period is a downwardly biased estimate of the true median holding period since stocks held for long periods are more likely to be bought before or sold after the data period and therefore not counted in the sample averages. The average turnover rate for equity in these accounts is 6.5 percent per month, which corresponds to an average holding period of about 15 months.

12 At the time of this study CRSP data were available through 1994. For this reason two-year subsequent returns are not calculated for sales dates in 1993 . 
Table V

\section{PGR and PLR When No New Stock Is Purchased Within Three Weeks of Sale}

This table compares the aggregate Proportion of Gains Realized (PGR) to the aggregate Proportion of Losses Realized (PLR), where PGR is the number of realized gains divided by the number of realized gains plus the number of paper (unrealized) gains, and PLR is the number of realized losses divided by the number of realized losses plus the number of paper (unrealized) losses. In this table losses and gains are counted only if a no new purchase was made into a portfolio on the day of the sale or within three weeks following the sale. Paper (unrealized) gains and losses are counted for days on which qualifying sales were made. Realized gains, paper gains, losses, and paper losses are aggregated over time (1987-1993) and across all accounts in the dataset. PGR and PLR are reported for the entire year and for December only. For the entire year there are 8,336 realized gains, 10,240 paper gains, 7,553 realized losses, and 19,370 paper losses. For December there are 590 realized gains, 1,024 paper gains, 1,194 realized losses, and 1,863 paper losses. The $t$-statistics test the null hypotheses that the differences in proportions are equal to zero assuming that all realized gains, paper gains, realized losses, and paper losses result from independent decisions.

\begin{tabular}{lcc}
\hline & Entire Year & December \\
\hline PLR & 0.281 & 0.391 \\
PGR & 0.449 & 0.366 \\
Difference in proportions & -0.168 & 0.015 \\
$t$-statistic & -36 & 1.6 \\
\hline
\end{tabular}

The average excess returns to winners sold in Table VI are determined by calculating excess buy-and-hold returns over the periods subsequent to each profitable sale of each stock and then taking an average that weighs each observation equally. Many stocks are sold for a profit on more than one date; sometimes the same stock is sold for a profit on the same date by more than one investor. Each of these sales is counted as a separate observation. The same procedure applies to paper losses. The $p$-values in Table VI are estimated by bootstrapping an empirical distribution for the difference in average excess buy-and-hold returns to realized winners and paper losses. This empirical distribution is generated under the null hypothesis that subsequent excess returns to realized winners and paper losers are drawn from the same underlying distribution. The methodology is similar to that of Brock, Lakonishok, and LeBaron (1992) and Ikenberry, Lakonishok, and Vermaelen (1995). Lyon, Barber, and Tsai (1998) test the acceptance and rejection rates for this methodology and find that it performs well in random samples. For each stock in the sample for which CRSP return data are available, a replacement stock is drawn (with replacement) from the set of all CRSP stocks of the same size decile and same book-to-market quintile as the original stock. Using the replacement stocks together with the original observation dates, average excess buy-and-hold returns are calculated for the 84, 252, and 502 trading days following the dates on which sales for a profit or paper losses are observed. These averages, and their differences, constitute one observation from the empirical distribution. One thousand such observa- 
Table VI

\section{Ex Post Returns}

This table compares average returns in excess of the CRSP value-weighted index to stocks that are sold for a profit (winning stocks sold) and to stocks that could be, but are not, sold for a loss (paper losses). Returns are measured over the 84, 252, and 504 trading days subsequent to the sale of a realized winner and subsequent to days on which sales of other stocks take place in the portfolio of a paper loser. $p$-values refer to the frequency with which differences in excess returns over the same periods in the empirical (bootstrapped) distributions exceed the difference in excess returns observed in the data.

\begin{tabular}{lccc}
\hline & $\begin{array}{c}\text { Performance over } \\
\text { Next 84 } \\
\text { Trading Days }\end{array}$ & $\begin{array}{c}\text { Performance over } \\
\text { Next 252 } \\
\text { Trading Days }\end{array}$ & $\begin{array}{c}\text { Performance over } \\
\text { Next 504 } \\
\text { Trading Days }\end{array}$ \\
\hline $\begin{array}{l}\text { Average excess return on } \\
\text { winning stocks sold }\end{array}$ & 0.0047 & 0.0235 & 0.0645 \\
Average excess return on & -0.0056 & -0.0106 & 0.0287 \\
$\quad$ paper losses & 0.0103 & 0.0341 & 0.0358 \\
$\begin{array}{l}\text { Difference in excess returns } \\
(p \text {-values })\end{array}$ & $(0.002)$ & $(0.001)$ & $(0.014)$ \\
\hline
\end{tabular}

tions are made. The null hypothesis is rejected at the $\alpha$ percent level if the average subsequent excess return to realized winners minus that to paper losers in the data set is greater than the $(1-\alpha)$ percentile average excess return to realized winners minus that to paper losers observed in the empirical distribution.

We saw in Table III (column 3) that investors are more likely to realize smaller, rather than larger, gains and losses. It may be that, due to regret aversion, investors are most loath to realize their greatest losses, and, due to tax consequences, they postpone realizing their greatest gains. Lower price ranges are likely to have a greater proportion of large losers and a smaller proportion of large winners than upper price ranges. Investors will therefore have a greater propensity to not sell losers in lower price ranges, and to not sell winners in higher price ranges.

Harris (1988) suggests that investors' reticence to sell losers may be due to their sensitivity to higher trading costs at lower stock prices. Table VII reports PGR and PLR for different price ranges and return ranges for January through November. Stocks with a price less than or equal to $\$ 10$, with prices greater than $\$ 10$ and less than or equal to $\$ 25$, and with prices higher than $\$ 25$, represent, respectively, 36 percent, 35 percent, and 29 percent of the data set. Partitioning on magnitude of return controls for the disproportionate numbers of large losers in the lower price range and of large winners in the top price range. The ranges for absolute value of return are: 0 to $0.15,0.15$ to $0.30,0.30$ to 0.50 , and greater than 0.50 . We see that in fourteen of fifteen partitions winners are realized at a higher rate than losers. This difference is statistically significant in thirteen partitions. When comparing winners and losers of similar magnitude, investors appear to prefer to sell winners and hold losers even when trading costs for both are about the same. 
Table VII

\section{PGR and PLR Partitioned by Price and Return}

This table compares the aggregate Proportion of Gains Realized (PGR) to the aggregate Proportion of Losses Realized (PLR), where PGR is the number of realized gains divided by the number of realized gains plus the number of paper (unrealized) gains, and PLR is the number of realized losses divided by the number of realized losses plus the number of paper (unrealized) losses. The data are partitioned on stock price and on absolute value of the return to date $(R)$, for all accounts, 1987-1993, January through November only. The $t$-statistics test the null hypotheses that the differences in proportions are equal to zero assuming that all realized gains, paper gains, realized losses, and paper losses result from independent decisions.

\begin{tabular}{lcccr}
\hline & $|R| \leq 0.15$ & $0.15<|R| \leq 0.30$ & $0.30<|R| \leq 0.50$ & $0.50 \leq|R|$ \\
\hline Price $\leq \$ 10$ & & & & 0.109 \\
PLR & 0.141 & 0.129 & 0.295 & 0.030 \\
PGR & 0.267 & 0.257 & -0.186 & -0.252 \\
Difference & -0.126 & -0.128 & 11.7 & 17.5 \\
$t$-statistic & 13.0 & 10.2 & & 0.058 \\
$\$ 10 \leq$ Price $\leq \$ 25$ & & & 0.076 & 0.135 \\
PLR & 0.138 & 0.105 & 0.172 & -0.077 \\
PGR & 0.222 & 0.186 & -0.096 & 11.3 \\
Difference & -0.084 & -0.081 & 13.1 & 0.049 \\
$t$-statistic & 16.9 & 13.1 & & 0.055 \\
$\$ 25 \leq$ Price & & & 0.104 & 0.006 \\
PLR & 0.125 & 0.104 & 0.081 & 0.61 \\
PGR & 0.197 & 0.126 & 0.023 & -3.2 \\
Difference & -0.072 & -0.022 & & \\
$t$-statistic & 19.4 & 4.5 & & \\
\hline
\end{tabular}

There is another way to contrast the hypothesis that losses are realized more slowly due to the higher transactions costs with the two behavioral hypotheses. We can look at the rates at which investors purchase additional shares of stocks they already own. The proportion of gains purchased again (PGPA) and the proportion of losses purchased again (PLPA) can be calculated in a manner analogous to how PGR and PLR are calculated. When a stock already in the portfolio is purchased again it is counted as a gain purchased again or a loss purchased again. On days when purchases are made, stocks already in the portfolio for which additional shares are not repurchased are counted as gains or losses potentially purchased again. Thus:

$\frac{\text { Gains Purchased Again }}{\underset{\text { Gains Purchased }}{\text { Again }}+\begin{array}{c}\text { Gains Potentially } \\ \text { Purchased Again }\end{array}}=\underset{\text { Proportion of Gains }}{\text { Purchased Again }}$ (PGPA)

$\frac{\text { Losses Purchased Again }}{\underset{\text { Losses Purchased }}{\text { Again }}+\begin{array}{c}\text { Losses Potentially } \\ \text { Purchased Again }\end{array}}=\stackrel{\begin{array}{c}\text { Proportion of Losses } \\ \text { Purchased Again }\end{array}}{\text { (PGPA) }}$


When these proportions are calculated, additional purchases of a particular stock in a particular account are not counted if they take place within one week of a previous purchase of the stock. This is done to avoid the possibility of counting a purchase order filled over more than one day as an additional purchase.

If investors avoid the higher transactions cost of low priced stocks we would expect PLPA to be less than PGPA. If, however, investors are more risk seeking for losing investments (prospect theory) or if they believe prices will revert (as do Andreassen's subjects), then PLPA will be greater than PGPA. This is the case. For the entire sample PLPA $=0.135$ and PGPA $=$ 0.094. If we assume that all decisions to purchase or not purchase additional stock are independent, the hypothesis that these two proportions are equal can be rejected with a $t$-statistic of 19 . This supports the two behavioral theories, but not the transaction cost hypothesis. ${ }^{13}$

In Table III we saw that investors tend to sell their larger gains and losses at a slower rate than their smaller gains and losses. Prospect theory does not predict that investors realize their large gains more slowly than their small gains. Nor does a belief in mean reversion predict this. If, however, investors believe that stocks that perform moderately well will revert, but those that perform unusually well will trend, ${ }^{14}$ they might sell their small winners and hold their larger ones. These beliefs could then also lead them to buy fewer additional shares of small winners and more additional shares of larger winners. To test this I partition winning investments into large or small winners using the mean unrealized winners' return of 0.47 as a break point (see Table III). Similarly I partition losers into large and small losers using -0.39 as a break point. Small winners are repurchased at a rate of 0.112 , large winners are repurchased at a rate of 0.043 . Small losers are repurchased at a rate of 0.172 and large losers at 0.067 . The difference in the rates at which large and small gains are realized is highly significant ( $t$ equals 26, assuming independence); so, too, is the difference in the rate at which large and small losses are realized ( $t$ equals 39 ). These investors do not tend to buy additional shares of big winners. This is not consistent with the hypothesis that they believe small winners will revert but large winners will perform well, however other factors may be working against the hypothesis. Investors who are in the habit of buying additional shares of stocks they already own may reach their limit of additional purchases before these stocks have an opportunity to make large gains (or losses). Regret aversion may also influence investors to not buy additional shares of big winners. For example, suppose an investor buys 100 shares of stock A at $\$ 100$ per share. Then stock A appreciates to $\$ 150$. The investor may believe stock A will

\footnotetext{
${ }^{13}$ For the same reasons as discussed in Section III B, these decisions will not always be independent. So the $t$-statistic of 19 overstates the actual statistical significance.

${ }^{14}$ In this vein Barberis, Shleifer, and Vishny (1996) develop a model in which investors believe that earnings switch between two regimes, one mean reverting and the other trend following.
} 
continue to appreciate but he may still refrain from buying an additional 100 shares, for if he does purchase more shares, he will more poignantly regret that he didn't buy them at $\$ 100$ per share to begin with. The greater the difference between the original and additional purchase prices, the greater is this potential regret.

The results presented so far are not able to distinguish between the two behavioral hypotheses. Both prospect theory and a belief in mean reversion predict that investors will hold their losers too long and sell their winners too soon. Both predict that investors will purchase more additional shares of losers than of winners. However a belief in mean reversion should apply to stocks that an investor does not already own as well as those she does, but prospect theory applies only to the stocks she owns. Thus a belief in mean reversion implies that investors will tend to buy stocks that had previously declined even if they don't already own these stocks, and prospect theory makes no prediction in this case. Odean (1997) finds that this same group of investors tends to buy stocks that have, on average, outperformed the CRSP value-weighted index by about 25 percent over the previous two years. This would appear inconsistent with a simple belief in mean reversion. (It is, though, consistent with a belief that big winners will continue to perform well.)

\section{Discussion}

This paper examines the behavior of individual investors and finds that investors exhibit disposition effects; that is, they realize their profitable stocks investments at a much higher rate than their unprofitable ones, except in December. The extent to which this behavior affects market prices depends on the trading activities of other market participants such as professional traders and institutional investors. If the disposition effect holds in aggregate it may contribute to the positive relationship between price change and volume identified by Lakonishok and Smidt (1986) and by Ferris et al. (1988). The disposition effect could also be a cause of the positive correlation between price changes and volume in other markets such as residential real estate. Case and Shiller (1988) report evidence of disposition effects from interviews with homeowners in boom and post-boom real estate markets.

By affecting supply, the disposition effect may also contribute to market stability near prices at which substantial trading has previously taken place. If many investors buy a stock at a particular price, that price may become their reference point. If the stock falls below this reference point, these investors will be averse to selling for a loss, reducing the supply of potential sellers. A reduced supply of potential sellers could slow further price decreases. On the other hand, if the stock rises above the reference point, these investors will be more willing to sell, increasing the supply of potential sellers, and possibly slowing further price increases. If these investors have private information about the future prospects of a company whose stock 
they hold, the disposition effect may slow the rate at which this information is incorporated into price. For example, investors with negative information may be unwilling to sell a stock if its price is below their reference point. In not selling the stock, these investors will fail to signal their negative information to the market, and there could be a delay before that information is reflected in prices.

Though the disposition effect may influence market prices, its economic significance is likely to be greatest for individual investors. To get a rough idea of the economic costs of the loss aversion, let us imagine that a hypothetical investor is choosing to sell one of two stocks. The first of these stocks behaves like the average realized winner in this data set and the other like the average paper loser. The investor wishes to sell $\$ 1,000$ worth of stock after commissions and that happens to be what his position in each stock is currently worth. Suppose he is averse to realizing losses and so sells the winning stock. If his experience is similar to that of the average investor in this data set, his return on the sale will be 0.277 (Table III, third column). Since the stock is currently worth $\$ 1000$, its purchase price must have been $\$ 783$, and his capital gain is $\$ 217$. If he instead chooses to sell $\$ 1,000$ worth of the losing stock, his return will be -0.393 , with a purchase price of $\$ 1,647$, and a capital loss of $\$ 647$. One year later the (losing) stock that he held will have, on average, a return 1 percent below the market (Table VI); the winning stock that he sold will have, on average, a return 2.4 percent above the market. Marginal tax rates for capital gains for investors in this sample vary from 0 to 28 percent, plus state taxes. Assume that our investor's marginal tax rate is 15 percent and that he has taxable gains against which to offset losses. Then by choosing to sell the winning stock rather than the loser, he gives up an immediate tax savings of $\$ 130$. Suppose that whichever stock the investor does not sell now, he will sell in one year; then the investor is paying $\$ 130$ in taxes one year earlier than he otherwise would. If he can expect a return of 8 percent on his money, choosing not to defer these taxes costs him about $\$ 10$. In addition to this, over the next year the investor's return on the stock he holds (the loser) is $\$ 34$ less than if he had held the other stock (the winner). Using $\$ 1,000$ as a basis, and including the value of the immediate tax savings $(\$ 10)$ as well as the anticipated difference in capital gains $(\$ 34)$, the investor's return is about 4.4 percent higher over the next year if he sells the loser rather than the winner. The benefits of deferring taxes may be even higher if the investor chooses to delay realizing his gains for more than one year. On the other hand, a habit of regular loss realizations may reduce the magnitude of available capital losses.

The trading records analyzed in this paper are obtained from a discount brokerage house. This avoids the need to consider agency issues that influence institutional investors or to disentangle the decisions and motivations of individual investors from those of their retail brokers. It would be illuminating to repeat this study with data on institutional trading and with data from a retail brokerage house. 


\section{Conclusion}

This paper finds that individual investors demonstrate a significant preference for selling winners and holding losers, except in December when taxmotivated selling prevails. This investor behavior does not appear to be motivated by a desire to rebalance portfolios or by a reluctance to incur the higher trading costs of low priced stocks. Nor is it justified by subsequent portfolio performance. It leads, in fact, to lower returns, particularly so for taxable accounts.

\section{REFERENCES}

Andreassen, Paul, 1987, On the social psychology of the stock market: Aggregate attributional effects and the regressiveness of prediction, Journal of Personality and Social Psychology 53, 490-496.

Andreassen, Paul, 1988, Explaining the price-volume relationship: The difference between price changes and changing prices, Organizational Behavior and Human Decision Processes 41, 371-389.

Andreassen, Paul, 1990, Judgmental extrapolation and market overreaction: On the use and disuse of news, Journal of Behavioral Decision Making 3, 153-174.

Badrinath, S., and Wilber Lewellen, 1991, Evidence on tax-motivated securities trading behavior, Journal of Finance 46, 369-382.

Barberis, Nicholas, Andre Shleifer, and Robert Vishny, 1996, A model of investor sentiment with both underreaction and overreaction, Working paper, University of Chicago.

Benartzi, Shlomo, and Richard Thaler, 1995, Myopic loss aversion and the equity premium puzzle, Quarterly Journal of Economics 110, 73-92.

Bremer, Marc, and Kato Kiyoshi, 1996, Trading volume for winners and losers on the Tokyo Exchange, Journal of Financial and Quantitative Analysis 31, 127-142.

Brock, William, Josef Lakonishok, and Blake LeBaron, 1992, Simple technical trading rules and the stochastic properties of stock returns, Journal of Finance 47, 1731-1764.

Case, Karl, and Robert Shiller, 1988, The behavior of home buyers in boom and post-boom markets, New England Economic Review November/December, 29-46.

Constantinides, George, 1984, Optimal stock trading with personal taxes: Implications for prices and the abnormal January returns, Journal of Financial Economics 13, 65-69.

DeBondt, Werner, and Richard Thaler, 1985, Does the stock market overreact?, Journal of Finance 40, 793-807.

DeBondt, Werner, and Richard Thaler, 1987, Further evidence on investor overreaction and stock market seasonality, Journal of Finance 42, 557-581.

Dyl, Edward, 1977, Capital gains taxation and the year-end stock market behavior, Journal of Finance 32, 165-175.

Ferris, Stephen, Robert Haugen, and Anil Makhija, 1988, Predicting contemporary volume with historic volume at differential price levels: Evidence supporting the disposition effect, Journal of Finance 43, 677-697.

Harris, Lawrence, 1988, Discussion of predicting contemporary volume with historic volume at differential price levels: Evidence supporting the disposition effect, Journal of Finance 43, $698-699$.

Heisler, Jeffrey, 1994, Loss aversion in a futures market: An empirical test, Review of Futures Markets 13, 793-822.

Ikenberry, David, Josef Lakonishok, and Theo Vermaelen, 1995, Market underreaction to open market share repurchases, Journal of Financial Economics 39, 181-208.

Jegadeesh, Narasimhan, and Sheridan Titman, 1993, Returns to buying winners and selling losers: Implications for stock market efficiency, Journal of Finance 48, 65-91. 
Kahneman, Daniel, and Amos Tversky, 1979, Prospect theory: An analysis of decision under risk, Econometrica 46, 171-185.

Lakonishok, Josef, and Seymour Smidt, 1986, Volume for winners and losers: Taxation and other motives for stock trading, Journal of Finance 41, 951-974.

Lyon, John, Brad Barber, and Chih-Ling Tsai, 1998, Improved methods for tests of long-run abnormal stock returns, Journal of Finance, forthcoming.

New York Stock Exchange Fact Book, 1995, (New York Stock Exchange, Inc., New York, N.Y.).

Odean, Terrance, 1997, Do investors trade too much?, Working paper, University of California, Davis.

Poterba, James, 1987, How burdensome are capital gains taxes? Evidence from the United States, Journal of Public Economics 33, 157-172.

Schlarbaum, Gary, Wilber Lewellen, and Ronald Lease, 1978, Realized returns on common stock investments: The experience of individual investors, Journal of Business 51, 299-325.

Shefrin, Hersh, and Meir Statman, 1985, The disposition to sell winners too early and ride losers too long: Theory and evidence, Journal of Finance 40, 777-790.

Starr-McCluer, Martha, 1995, Tax losses and the stock portfolios of individual investors, Working paper, Federal Reserve Board of Governors.

Thaler, Richard, 1985, Mental accounting and consumer choice, Marketing Science 4, 199-214.

Weber, Martin, and Colin Camerer, 1998, The disposition effect in securities trading: An experimental analysis, forthcoming Journal of Economic Behavior and Organization. 